\title{
ANÁLISE FÍSICO-QUÍMICA E MICROSCÓPICA DA ÁGUA DE PROCESSO DE INDÚSTRIA DE BENEFICIAMENTO DE ARROZ
}

\author{
L. BARTMER ${ }^{1}$, L. P. FURMAN ${ }^{1}$, R. R. LIMA ${ }^{1}$, L. M. RODRIGUES ${ }^{1}$, T. R. SOUZA ${ }^{1}$ \\ ${ }^{1}$ Universidade Federal do Pampa, Departamento de Engenharia Química, Campus Bagé \\ E-mail para contato: ligiabartmer@hotmail.com
}

\begin{abstract}
RESUMO - Este trabalho surgiu da parceria entre os cursos de Engenharia Química e Engenharia de Produção da UNIPAMPA, Campus Bagé-RS e uma indústria de beneficiamento de arroz do Estado do RS. O objetivo do trabalho foi realizar análises físico-químicas e microscópica da água tratada pela indústria, destinada ao processo de parboilização do arroz. Por meio dos resultados obtidos avaliou-se a eficiência da estação de tratamento de água (ETA) de processo presente na indústria. Amostras de águas de abastecimento da indústria (proveniente de uma barragem) e da água tratada na ETA foram coletadas para análises. Para uma comparação de resultados foi igualmente analisada uma amostra de água destilada. Os parâmetros determinados foram $\mathrm{pH}$, condutividade elétrica, teor de sólidos dissolvidos, índice de turbidez, teor de oxigênio dissolvido e análise microscópica, para uma avaliação de presença de microrganismos e pequenos animais. Os resultados obtidos indicam que o tratamento empregado na ETA não está sendo eficiente e a atuação do grupo de trabalho busca melhorias para adequar os parâmetros da água tratada à Legislação vigente.
\end{abstract}

\section{INTRODUÇÃO}

A vida humana, assim como a de todos os seres vivos, depende da água, mas a dependência da água vai além das necessidades biológicas, englobando atividades de limpeza, higiene, irrigação, produção industrial, etc. No entanto, as atividades humanas muitas vezes comprometem a qualidade da água, com o despejo inadequado a partir de residências e indústrias, em rios e mares, de substâncias que contaminam o ambiente e prejudicam a saúde de organismos vivos. Por isso, a proteção de corpos hídricos (rios, lagos, mares) é um cuidado essencial à vida no planeta (Sobiologia, 2014).

A água potável é aquela popularmente chamada água pura. Para ser consumida, a água deve ser incolor, insípida (sem sabor) e inodora (sem cheiro). Ela deve estar livre de materiais tóxicos e microrganismos, como bactérias, protozoários, que são prejudiciais, mas deve conter sais minerais em quantidade necessária à saúde (BRAGA et al., 2002).

A água potável é encontrada em pequena quantidade no planeta e não está disponível infinitamente. Por ser um recurso limitado, o seu consumo deve ser planejado. A água potável deve ter certa quantidade de alguns sais minerais dissolvidos. A água sem qualquer outra substância dissolvida é chamada de água destilada (Sobiologia, 2014). 
A água é a substância mais abundante da matéria viva chegando a um percentual médio de 75\% desta. Atua como solvente universal dispersando compostos orgânicos e inorgânicos (LOPES, 2006).

Embora mais de $70 \%$ do planeta seja constituído de água, somente cerca de $3 \%$ desta, se encontra disponível para o aproveitamento humano. Além disso, com a exploração industrial, urbana, agrícola e o avanço das ciências médicas houve contribuição para o aumento populacional que, aumentando o consumo de água, tornando-a escassa e alvo de tratamentos (MOTA, 2000).

A forma como o homem usa e ocupa o solo se reflete diretamente na qualidade da água que se encontra a sua disposição (DI BERNARDO et al., 2002). Ao interferir no meio ambiente, lançando produtos tóxicos o homem vem alterando o meio onde vive, proporcionando condições ideais para aparecimento de doenças.

A água pode conter barro, areia e outras impurezas. Um grande perigo de contaminação da água está, por exemplo, na presença de produtos químicos tóxicos ou microrganismos que tornam a água poluída. Há varias fontes de poluição, como: a falta de tratamento de esgoto, a mineração, a extração e o transporte de petróleo, a poluição causada pelas indústrias, as estações de tratamento de efluentes, etc. (Sobiologia, 2014).

Os poluentes das águas mais comuns são os metais, materiais radioativos, poluentes orgânicos, como é o caso dos detergentes sintéticos, defensivos agrícolas, petróleo, corantes e os poluentes orgânicos biodegradáveis (BRAGA et al., 2002).

A qualidade das águas é representada por um conjunto de características, geralmente mensuráveis, de natureza química, física e biológica (INEA, 2013). Estes parâmetros determinam as características de potabilidade necessárias para que a água chegue até a população de uma maneira mais segura e confiável afim de que, possa ser utilizada no consumo humano e para atividades industriais. Esses parâmetros são regulamentados por normas e/ou padrões definidos em portarias do ministério da saúde (RICHTER \& NETTO, 1999).

No Brasil, a ANA (Agência Nacional de Águas, 2013) ajuda a manter o PNQA (Programa Nacional de Avaliação da Qualidade das Águas) programa implementado para atender as necessidades de monitoramento da qualidade da água no país, uma das principais questões da gestão dos recursos hídricos no Brasil.

O monitoramento da qualidade da água no Brasil esbarra em lacunas geográficas, cujas regiões ainda não são pesquisadas, e pela falta de verba e recursos para esse setor. Há também a carência de padronização de pesquisa e informações para a coleta e análises de laboratório entre as diferentes regiões do Brasil.

Os principais indicadores de qualidade da água, segundo o Laboratório da Qualidade da Água do Departamento de Engenharia Agrícola e Ambiental da Universidade Federal de Viçosa (2013), são divididos em parâmetros físicos (como temperatura, sabor, odor, cor, turbidez, presença de sólidos e condutividade elétrica), parâmetros químicos (como pH, alcalinidade, dureza, teores de cloretos, ferro, manganês, nitrogênio, fósforo e fluoretos, 
oxigênio dissolvido, matéria orgânica, demanda bioquímica de oxigênio, demanda química de oxigênio, componentes inorgânicos e componentes orgânicos) e parâmetros biológicos (como coliformes, algas e bactérias).

O tratamento de água industrial é um processo de recuperação da qualidade da água utilizada pela indústria. O tratamento da água deve ser orientado por um profissional da área, como um engenheiro químico, engenheiro ambiental, químico ou técnico químico.

No dia a dia a água é utilizada pela indústria em aplicações que vão desde o resfriamento de processos industriais até a simples limpeza. Este tipo de água pode conter metais pesados ou outros produtos tóxicos, e por isso necessita ser recuperada antes de seu lançamento na rede de esgotos ou nas vias fluviais (BRAGA et al., 2005; MOTA, 2000).

A água é um elemento fundamental em praticamente todos os setores industriais. Incentivadas por razões econômicas, diversas empresas passaram a conduzir programas de gestão dos seus recursos hídricos, implementando projetos de reuso, redução de perdas e racionalização do uso, obtendo reduções expressivas do consumo de água e dos lançamentos de efluentes ao meio ambiente (SHREVE \& BRINK, 1990).

Recebem a denominação de águas industriais aquelas que são utilizadas em plantas industriais para (RAMALHO, 1991): Geração de vapor e energia; Refrigeração e resfriamento; Processo produtivo; Lavagens e outros usos diversos. Os principais usos da água nas indústrias (METCALF \& EDDY, Inc. et al., 1991): Emulsificador de lubrificantes de equipamentos/selagem de bombas; Aquecimento (águas de caldeira); Resfriamento (águas de refrigeração); Lavagem de pátios e abatimento de poeira; Lavagem de frutas / hortaliças; Irrigação / Hidroponia / Aquicultura; Processos de fabricação, etc.

Os principais métodos utilizados no tratamento de águas industriais são (SHREVE \& BRINK, 1990): floculação; decantação/flotação; filtração; dosagem de produtos químicos e desinfecção; abrandamento, desmineralização e polimento de condensado; osmose reversa; ultra filtração; tratamento anti-corrosivo; tratamento para dureza.

O presente trabalho tem por finalidade analisar parâmetros físicos, químicos e microscópicos (como a presença de microrganismos) da água natural (proveniente de barragem) que serve de fonte de abastecimento à indústria de beneficiamento de arroz, e da água de processo industrial, para uma estimativa da eficiência do tratamento empregado.

\section{METODOLOGIA}

A amostra de água bruta a analisar foi coletada em barragem no sul do Estado do RS, fonte de abastecimento de indústria de beneficiamento de arroz. A amostra de água de processo (água coletada na barragem e submetida à estação de tratamento de águas da indústria) foi cedida pela indústria para análises.

As amostras de águas foram avaliadas quanto ao valor de $\mathrm{pH}$, índice de turbidez, condutividade elétrica, teor de sólidos dissolvidos, teor de oxigênio dissolvido, dureza, teor de cloretos e coloração. Análises por microscopia em microscópio ótico biológico e estereomicroscópio foram empregadas para avaliação da presença de microrganismos nas 
amostras de águas. Foram também realizadas análises físico-químicas em amostra de água destilada para uma comparação de resultados. A coloração das amostras foi avaliada visualmente.

A Portaria $\mathrm{n}^{\circ} .2914$ do ano de 2011 do Ministério da Saúde sobre os requisitos para a potabilidade da água foi utilizada para uma avaliação dos parâmetros medidos, pois a mesma é empregada pelos clientes da indústria beneficiadora de arroz para avaliação da água de processo.

Os equipamentos utilizados nas análises físico-químicas foram disponibilizados pela UNIPAMPA, Campus Bagé, sendo medidor de $\mathrm{pH}$ de bancada digital, turbidímetro digital, oxímetro digital e medidor de sólidos dissolvidos digital. A dureza das amostras de águas foi determinada por titulação com EDTA, e a concentração de cloretos, por titulação com $\mathrm{Ag}(\mathrm{NO})_{3}$.

\section{RESULTADOS}

$\mathrm{Na}$ avaliação físico-química foram quantificados e comparados alguns parâmetros da água bruta, da água de processo e de amostra de água destilada em laboratório (para simples comparação). Esses parâmetros podem ser visualizados na Tabela 1, juntamente com os limites indicados pela Legislação Federal, Portaria n ${ }^{\circ} .2914$ de 2011 do Ministério da Saúde.

Os resultados obtidos justificam a importância da melhoria do processo de tratamento de água da indústria, destinada ao processo produtivo. Avaliando-se os parâmetros e limites apresentados na Portaria $\mathrm{n}^{\circ}$. 2914/2011 MS, notam-se que quanto ao teor de sólidos dissolvidos e índice de turbidez o tratamento de água empregado pela indústria não é efetivo.

O valor da dureza total das águas apresentado na Tabela 1 classificam as amostras de águas como moles, sendo considerados baixos os níveis de cálcio e magnésio.

Tabela 1 - Características das malhas utilizadas nas simulações em CFD.

\begin{tabular}{|c|c|c|c|c|}
\hline Parâmetros físico-químicos & $\begin{array}{c}\text { Água bruta } \\
\text { (barragem) }\end{array}$ & $\begin{array}{c}\text { Água de } \\
\text { processo }\end{array}$ & $\begin{array}{c}\text { Água } \\
\text { destilada }\end{array}$ & $\begin{array}{c}\text { Portaria } \\
(2914 / 2011 \mathrm{MS})\end{array}$ \\
\hline \hline Dureza total $\left(\mathrm{mg} / \mathrm{L} \mathrm{CaCO}_{3}\right)$ & 40 & 33 & 0 & 500 \\
\hline $\mathrm{pH}$ & 7,88 & 7,90 & 5,40 & $6,0-9,5$ \\
\hline Condutividade elétrica $(\mu \mathrm{S} / \mathrm{cm})$ & 374 & 306 & 5,64 & - \\
\hline Índice de turbidez $(\mathrm{NTU})$ & 4,46 & 5,83 & 0,36 & 5 \\
\hline Teor de $\mathrm{O}_{2}$ dissolvido $(\mathrm{ppm})$ & 14,56 & 15,49 & 9,57 & - \\
\hline $\begin{array}{c}\text { Teor de sólidos dissolvidos } \\
(\mathrm{ppm})\end{array}$ & 178 & 158 & 4,22 & $1000 \mathrm{mg} / \mathrm{L}$ \\
\hline Teor de cloretos $(\mathrm{mg} / \mathrm{L})$ & 2,41 & 5,85 & 0 & 250 \\
\hline
\end{tabular}

Foi investigada por microscopia a presença de microrganismos nas amostras de águas. Larvas e mini crustáceos foram detectados na amostra de água de processo conforme mostra a Figura 1. 
Figura 1 - Análise microscópica da amostra de água de processo
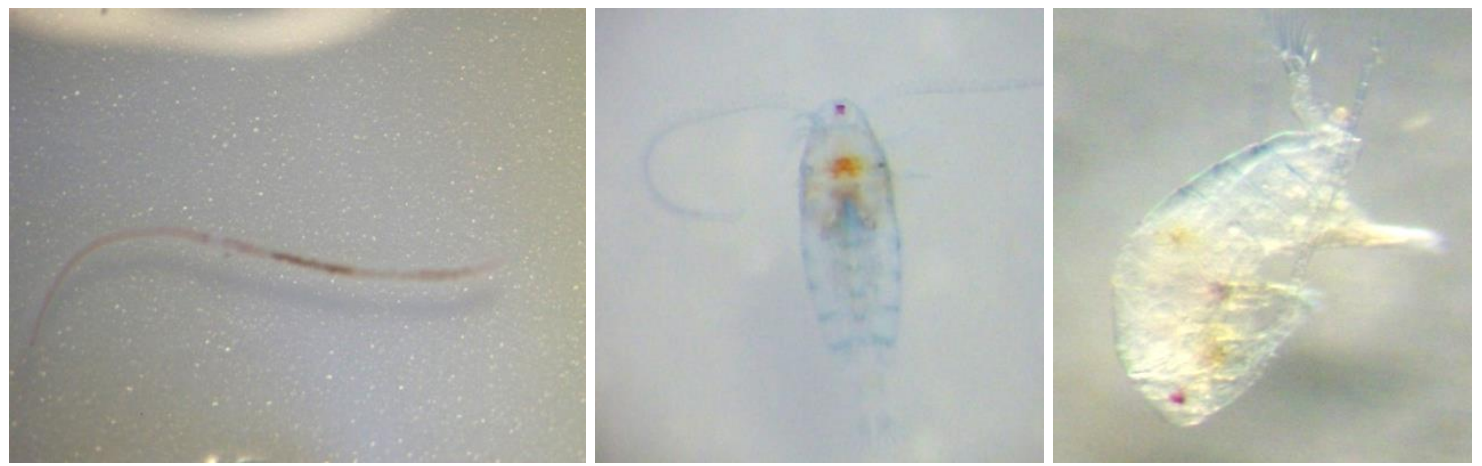

A coloração das amostras foi avaliada visualmente. Observa-se a coloração amarelada da amostra de água bruta e de processo, e a total transparência da água destilada conforme mostra a Figura 2.

Figura 2 - Comparação da coloração das amostras de águas

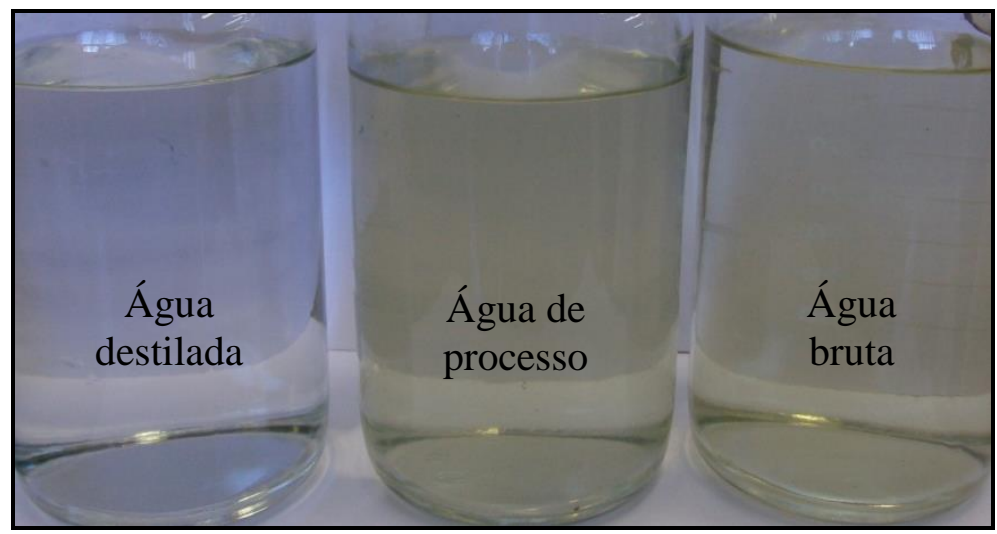

\section{CONSIDERAÇÕES FINAIS}

A caracterização das amostras de águas bruta e de processo reflete a baixa eficiência do processo de tratamento da água empregada pela empresa de beneficiamento de arroz. Alguns parâmetros avaliados tiveram seus valores melhorados após o tratamento proposto pela empresa, sendo: dureza total, condutividade elétrica, teor de $\mathrm{O}_{2}$ dissolvido e teor de sólidos dissolvidos. Nota-se o incremento no valor do teor de cloretos na água tratada e sua turbidez.

As etapas de tratamento de águas empregado na indústria de beneficiamento de arroz envolvem ajuste de $\mathrm{pH}$, floculação, decantação e filtração. Estima-se que provavelmente não haja tempo suficiente para a floculação e decantação dos contaminantes da água bruta, durante o seu tratamento, bem como a ocorrência da saturação dos meios filtrantes empregados na etapa de filtração. O emprego de carvão ativado no tratamento da empresa poderia auxiliar neste processo. Atualmente este material adsorvente não é utilizado, sendo utilizados apenas filtros contendo leitos de areias de diferentes granulometrias.

A continuidade do projeto de pesquisa e atuação do grupo de trabalho auxiliará a reavaliação das etapas do tratamento, inclusive com simulação em laboratório, em escala 
piloto, da estação de tratamento de água industrial, buscando enquadrar plenamente os parâmetros da água tratada na Legislação vigente. A presença de microrganismos na água tratada é um fator preocupante, e que deverá ser alvo de modificações no tratamento para a sua eliminação.

\section{REFERÊNCIAS}

ANA - Agência Nacional de Águas. Disponível em: <http://www.infoescola.com/ecologia/qualidade-da-agua-no-brasil/>. Acessado em: 05/12/2013.

AZEVEDO NETTO, José Martiniano; RICHTER, C. A. Tratamento de Água: Tecnologia Atualizada. São Paulo: Editora Edgar Blucher Ltda,1999, 332p.

BRAGA, Benedito; HESPANHOL, Ivanildo; CONEJO, João G. L.; et al. Introdução à Engenharia Ambiental. São Paulo: Prentice Hall, 2002, 336p.

Di BERNARDO, Luiz; DANTAS, Ângela Di Bernardo. Métodos e Técnicas de Tratamento de Água. $2^{\mathrm{a}}$ ed. Associação Brasileira de Engenharia Sanitária e Ambiental, São Carlos: Ed. Rima, 2005, 1566p.

INEA - Instituto Estadual do Ambiente. Disponível em: <http://www.inea.rj.gov.br/fma/qualidade-agua.asp>. Acessado em: 01/12/2013.

Laboratório da Qualidade da Água do Departamento de Engenharia Agrícola e Ambiental da Universidade Federal de Viçosa. Disponível em: <http://www.ufv.br/dea/lqa/qualidade.htm>. Acessado em: 01/12/2013.

LOPES, Sônia. Biologia. Volume Único. São Paulo: Editora Saraiva, 2006, 396p.

METCALF \& EDDY, INC.; TCHOBANOGLOUS, George; BURTON, Franklin; STENSEL, David H. Wastewater Engineering - Treatment, Disposal and Reuse. McGraw-Hill, 1991.

MOTA, Suetônio. Introdução à Engenharia Ambiental. Rio de Janeiro: ABES, 2000, 416p.

RAMALHO, Rubens Sette. Introduction to Wastewater Treatment Processes. Academic Press, 1991, 409p.

SHREVE, Randolph Norris \& BRINK Jr, Joseph A. Indústrias de Processos Químicos. Rio de Janeiro: Ed. Guanabara Dois, 1990.

Sobiologia - Disponível em: <http://www.sobiologia.com.br/conteudos/Agua〉. Acessado em 07/01/2017. 